\title{
Temperature profiling of the atmospheric boundary layer with rotational Raman lidar during the $\mathrm{HD}(\mathrm{CP})^{2}$ Observational Prototype Experiment
}

\author{
E. Hammann ${ }^{1}$, A. Behrendt ${ }^{1}$, F. Le Mounier ${ }^{2}$, and V. Wulfmeyer ${ }^{1}$ \\ ${ }^{1}$ University of Hohenheim, Institute of Physics and Meteorology, Garbenstrasse 30, 70599 Stuttgart, Germany \\ ${ }^{2}$ Laboratoire de Météorologie Dynamique, C.N.R.S, Paris, France
}

Correspondence to: E. Hammann (eva.hammann@uni-hohenheim.de)

Received: 22 July 2014 - Published in Atmos. Chem. Phys. Discuss.: 21 November 2014

Revised: 6 February 2015 - Accepted: 16 February 2015 - Published: 12 March 2015

\begin{abstract}
The temperature measurements of the rotational Raman lidar of the University of Hohenheim (UHOH RRL) during the High Definition of Clouds and Precipitation for advancing Climate Prediction ( $\left.\mathrm{HD}(\mathrm{CP})^{2}\right)$ Observation Prototype Experiment (HOPE) in April and May 2013 are discussed. The lidar consists of a frequency-tripled Nd:YAG laser at $355 \mathrm{~nm}$ with $10 \mathrm{~W}$ average power at $50 \mathrm{~Hz}$, a twomirror scanner, a $40 \mathrm{~cm}$ receiving telescope, and a highly efficient polychromator with cascading interference filters for separating four signals: the elastic backscatter signal, two rotational Raman signals with different temperature dependence, and the vibrational Raman signal of water vapor. The main measurement variable of the UHOH RRL is temperature. For the HOPE campaign, the lidar receiver was optimized for high and low background levels, with a novel switch for the passband of the second rotational Raman channel. The instrument delivers atmospheric profiles of water vapor mixing ratio as well as particle backscatter coefficient and particle extinction coefficient as further products. As examples for the measurement performance, measurements of the temperature gradient and water vapor mixing ratio revealing the development of the atmospheric boundary layer within $25 \mathrm{~h}$ are presented. As expected from simulations, a reduction of the measurement uncertainty of $70 \%$ during nighttime was achieved with the new low-background setting. A two-mirror scanner allows for measurements in different directions. When pointing the scanner to low elevation, measurements close to the ground become possible which are otherwise impossible due to the non-total overlap of laser beam and receiving telescope field of view in the near range.
\end{abstract}

An example of a low-level temperature measurement is presented which resolves the temperature gradient at the top of the stable nighttime boundary layer $100 \mathrm{~m}$ above the ground.

\section{Introduction}

In recent years, different techniques for measuring the atmospheric temperature profile with lidar have been developed, namely the rotational Raman technique, the integration technique (using elastic and Raman signals), and the resonance fluorescence technique, as well as the high-spectralresolution lidar (HSRL) technique and differential absorption lidar (DIAL) (see Behrendt, 2005, for an overview). For daytime measurements in the troposphere, rotational Raman lidar (RRL) is presently the most reliable technique. Its capabilities in providing temperature profiles with high temporal and spatial resolution and low systematic and noise errors during night- and daytime even within aerosol layers and thin clouds are superior so far to all other techniques, particularly where measurements from the surface to the lower troposphere are concerned (Behrendt and Reichardt, 2000; Behrendt et al., 2002, 2004; Di Girolamo et al., 2004; Arshinov et al., 2005; Radlach et al., 2008).

Most rotational Raman systems operate at wavelengths of 532 or $355 \mathrm{~nm}$, the second and third harmonic wavelengths of Nd:YAG lasers. UV systems are able to perform daytime measurements with lower uncertainties due to the higher backscatter cross section and less solar background (Zeyn et al., 1996; Behrendt, 2005). The rotational Raman lidars of 
NASA's Goddard Space Flight Center (Di Girolamo et al., 2004), of the University of Hohenheim (UHOH; Radlach et al., 2008), of the University of Basilicata (Di Girolamo et al., 2009), of Xi' an University (Mao et al., 2009), and of Hampton University (Su et al., 2013) all operate in the UV with interference-filter polychromators. Rotational Raman lidars at $532 \mathrm{~nm}$ show lower performance during daytime but reach a larger range at night than an UV system due to the higher laser power available at $532 \mathrm{~nm}$ compared to $355 \mathrm{~nm}$, higher efficiency in signal separation, and lower atmospheric extinction. Some of the systems at $532 \mathrm{~nm}$ are also based on interference filters (Behrendt and Reichardt, 2000; Behrendt et al., 2002, 2004; Achtert et al., 2013), and some employ double-grating polychromators (Balin et al., 2004; Arshinov et al., 2005).

Daytime temperature measurements are the main focus of the RRL of UHOH. But besides temperature, also the particle backscatter coefficient and the particle extinction coefficient can be measured independently. Furthermore, the system was extended recently with a water vapor Raman channel. For water vapor measurements, two different lidar techniques are available: the DIAL technique and the Raman lidar technique. While water vapor Raman lidar uses the vibrational Raman backscatter signals of water vapor (e.g., Melfi et al., 1969; Whiteman et al., 1992; Turner and Goldsmith, 1999; Leblanc and McDermid, 2008), the DIAL technique (Schotland, 1974; Wulfmeyer and Bösenberg, 1998; Behrendt et al., 2009; Wagner et al., 2013) relies on the different absorption of water vapor at two nearby wavelengths. In contrast to water vapor (WV) DIAL, whose self-calibrating property leads to a high accuracy of the measurements (Bhawar et al., 2011), a water vapor Raman lidar has to be calibrated and shows also lower performance during daytime. However, the laser transmitter is less complex, and, if a certain lidar system already contains rotational Raman channels, only one more detection channel is needed to derive in addition the water vapor mixing ratio (Behrendt et al., 2002). Thus it was decided to extend the UHOH RRL with a water vapor channel. Furthermore, this capability permits relative humidity measurements, which are, e.g., useful for aerosol (Wulfmeyer and Feingold, 2000) and convection initiation studies (Behrendt et al., 2011; Corsmeier et al., 2011). In parallel to the RRL, the UHOH has developed also a water vapor DIAL (Wagner et al., 2013), from which recent measurements are presented in Muppa et al. (2014).

Within the High Definition of Clouds and Precipitation for advancing Climate Prediction $\left(\mathrm{HD}(\mathrm{CP})^{2}\right)$ project, a new model for high-resolution weather forecasts will be developed (Stevens and Bony, 2013) and other model systems will be tested (Schwitalla and Wulfmeyer, 2014). To verify the model, high-resolution data sets are required. The $\mathrm{HD}(\mathrm{CP})^{2}$ Observation Prototype Experiment (HOPE), which provides such a data set, took place during April and May 2013 in the area around the Research Center Jülich in north- west Germany. The area already had an existing infrastructure of dense standard meteorological instrumentation.

Both systems of UHOH were operated together in the HOPE field campaign and thus provided a synergetic data set of thermodynamic properties of the atmosphere. The lidars were located at one supersite $\left(50^{\circ} 53^{\prime} 50.55^{\prime \prime} \mathrm{N}\right.$, $6^{\circ} 27^{\prime} 50.27^{\prime \prime} \mathrm{E}, 110 \mathrm{~m}$ above sea level) close to the village of Hambach together with the KITcube, an instrument suite of the Karlsruhe Institute of Technology (KIT) (Kalthoff et al., 2013). The site was on a hillside and elevated above the surroundings by 10 to $15 \mathrm{~m}$. The RRL and the WV DIAL of UHOH were collocated with a Doppler lidar from KIT to acquire a complete data set of temperature, water vapor content, and vertical wind for the determination of fluxes of sensible and latent heat (e.g., Behrendt et al., 2011). It was also the launch site for radiosoundings.

The purpose of this paper is to introduce the measurement performance of the UHOH RRL during HOPE and present highlights of the measurements. One highlight was the application of a novel switch for low- and high-background RRL. During the 18 intensive observation periods more than $200 \mathrm{~h}$ of measurements were collected. Measurements took place in the time between sunrise and sunset and were stopped in the case of rain or continuing dense cloud cover. In addition there were two night-long measurements. On one day, RHI (range-height indicator) scans were performed. During one day and one night, the lidar was pointed at a low elevation above the ground. Water vapor measurement started at the beginning of May; therefore only $100 \mathrm{~h}$ of water vapor data is available. Case studies using the combination of data from the instrument set - and also from the other two supersites - are in preparation and will be presented later based on the results shown here.

The main research interest of our institute is land-surfaceatmosphere feedback, which requires measurements of landsurface exchange, the surface layer, the atmospheric boundary layer, and the lower free troposphere. For investigating not only mean profiles or mean three-dimensional fields but also the turbulent features of the convective boundary layer, instruments providing data with high temporal and spatial resolution in conditions of high-background light are needed. The rotational Raman lidar of $\mathrm{UHOH}$ was optimized for such conditions. A new technical feature, which was implemented during the HOPE campaign, was a switch to optimize the performance of the temperature measurements for low- and high-background conditions. Detailed simulations were performed which showed that it is favorable to use another pair of filter center wavelengths in low-background conditions compared to cases with high solar background. The change between the settings can be made in a few minutes. Thus, it was possible to switch easily between the settings and acquire continuous time periods of data which included such changes.

This paper is structured as follows: in Sect. 2 the new setup of the UHOH RRL is explained. Also the simulations for two 


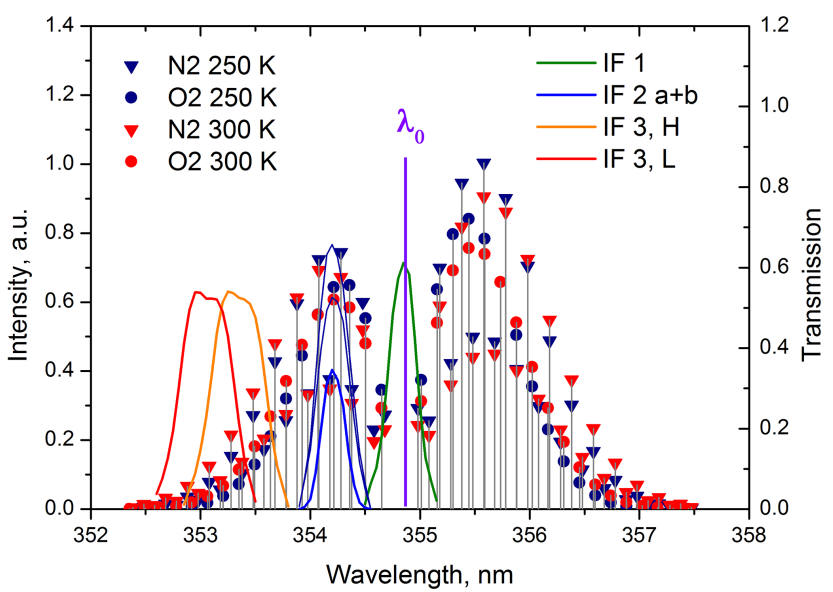

Figure 1. Rotational Raman spectrum of atmospheric nitrogen and oxygen for an excitation wavelength $\lambda_{0}$ of $354.83 \mathrm{~nm}$ and for two temperatures ( 250 and $300 \mathrm{~K}$ ). Transmission curves of the interference filters are shown for comparison. Although the Stokes lines $\left(\lambda>\lambda_{0}\right)$ are more intense, anti-Stokes lines $\left(\lambda<\lambda_{0}\right)$ are used by us to avoid possible measurement errors due to fluorescence (Immler et al. 2005). For IF3, the filter positions for both the low- and highbackground settings are shown ( $\mathrm{L}$ and $\mathrm{H}$, respectively).

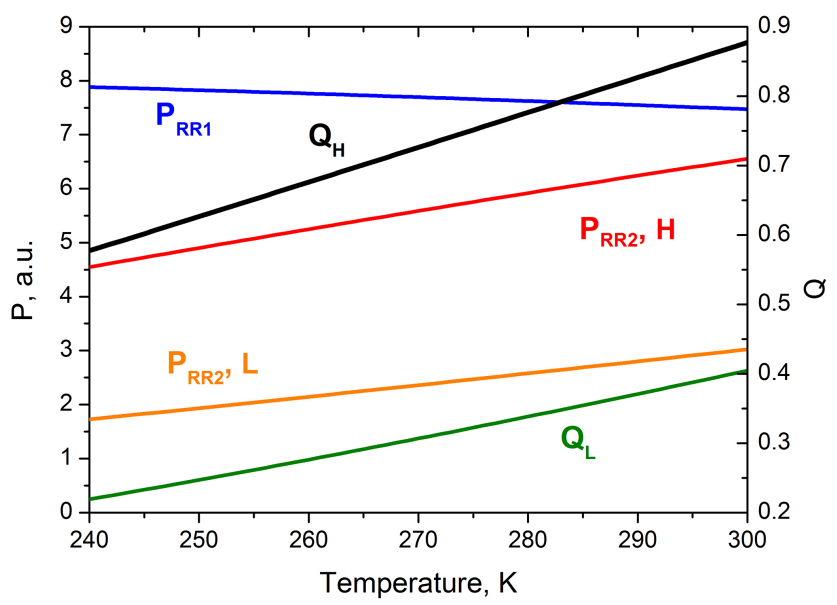

Figure 2. Simulated signal intensities for the filter configurations shown in Fig. 1: rotational Raman signal intensities for the $\mathrm{H}$ and $\mathrm{L}$ setting and corresponding ratios $Q=P_{\mathrm{RR} 2} / P_{\mathrm{RR} 1}$.

settings for the second rotational Raman channel are presented. Section 3 discusses the experimental results of the new system. Section 4 gives a short summary.

\section{Methods and performance simulations}

\subsection{Methods}

The rotational Raman lidar of $\mathrm{UHOH}$ makes use of the rotational Raman technique for deriving atmospheric temperature profiles (Cooney, 1972). Two parts of the rotational Raman spectrum of air with different temperature depen- dency are acquired (see Fig. 1). By taking the ratio of the two signals (Fig. 2) and calibrating it, the temperature is obtained without further assumptions about the state of the atmosphere. Figure 2 shows how the rotational Raman signals $P_{\mathrm{RR} 1}$ and $P_{\mathrm{RR} 2}$ depend on the temperature. For $P_{\mathrm{RR} 2}$ there are the two settings shown in Fig. 1 with different central wavelengths CWL2: one for low-background (L) and one for high-background $(\mathrm{H})$ conditions. The setting $\mathrm{L}$ results in a lower signal intensity in the second Raman channel. Also the ratio $Q$ between $P_{\mathrm{RR} 2}$ and $P_{\mathrm{RR} 1}$ is lower and has a different slope than the one for the $\mathrm{H}$ setting. There are several formulas in use for the calibration (Behrendt and Reichardt, 2000; Behrendt, 2005). For temperature measurements up to a few kilometers altitude, the following equation can be used:

$Q(T)=\exp \left(a-\frac{b}{T}\right)$,

where $Q$ is the ratio between the background-corrected signals in the Raman channels RR2 and RR1, and $a$ and $b$ are calibration constants. This equation is exact for the ratio of two single rotational Raman lines. If several rotational Raman lines are extracted by the two channels, more complicated equations with more constants are needed when temperature measurements are made over a larger range of temperatures (Behrendt and Reichardt, 2000; Behrendt, 2005). This is not the purpose here, so this equation can still be used and results in a high accuracy of the inversion. Therefore the atmospheric temperature can be derived from $Q$ by rearranging Eq. (1) to

$T=\frac{b}{a-\ln (Q)}$.

The statistical error of the temperature measurements can be determined from the signal intensities of the photon-counting data and applying Poisson statistics. For a signal with count number $s$, the $1 \sigma$ statistical error is

$\Delta s=\sqrt{s}$.

This results in a noise error for the temperature $\Delta T$ (Behrendt et al., 2002) of

$\Delta T=\frac{\partial T}{\partial Q} Q \sqrt{\frac{P_{\mathrm{RR} 1}+P_{\mathrm{B} 1}}{P_{\mathrm{RR} 1}^{2}}+\frac{P_{\mathrm{RR} 2}+P_{\mathrm{B} 2}}{P_{\mathrm{RR} 2}^{2}}}$.

$P_{\mathrm{RR} 1}$ is the background-corrected signal in the first Raman channel, $P_{\mathrm{B} 1}$ the background in this channel, and $P_{\mathrm{RR} 2}$ and $P_{\mathrm{B} 2}$ are the same for the second Raman channel. This equation is valid if $\Delta P_{\mathrm{B}}$ is 0 , which is a valid approximation if the background is calculated from a high number of bins. One can see from Eq. (4) that the error $\Delta T$ scales with

$\Delta T \sim \frac{1}{\sqrt{P t A \eta}}$, 


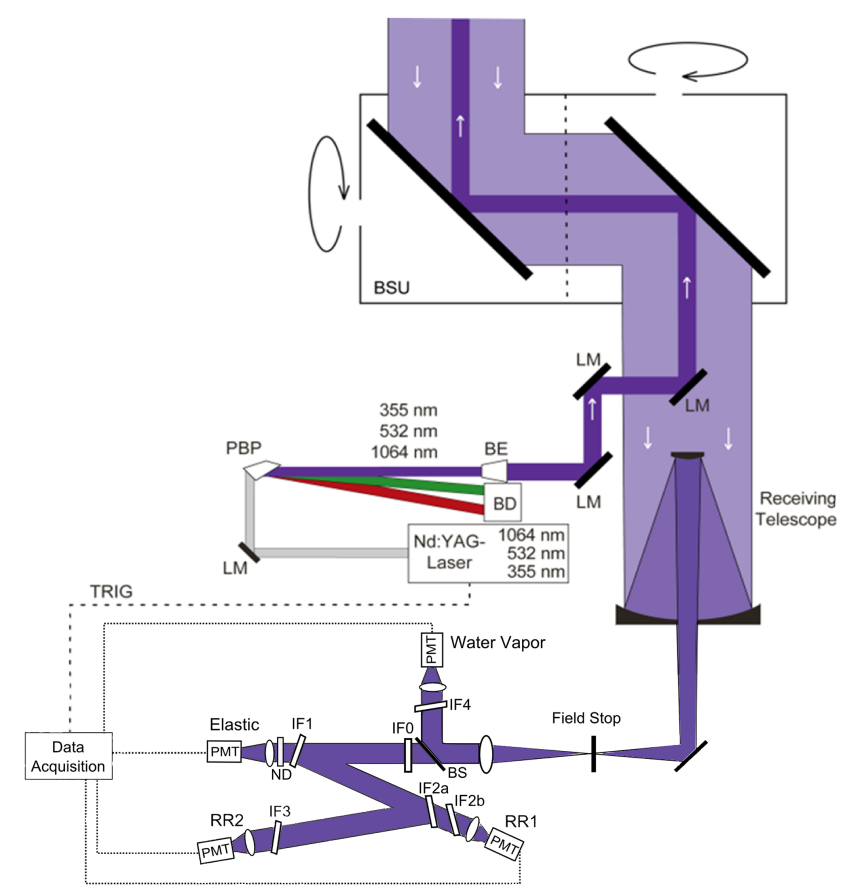

Figure 3. Setup of the rotational Raman lidar of the University of Hohenheim. LM stands for laser mirror, and the wavelengths are separated by a Pellin-Broca prism. Whereas 532 and $1064 \mathrm{~nm}$ are sent to a beam dump (BD), $355 \mathrm{~nm}$ is expanded by a beam expander (BE) and sent to the atmosphere through the beam steering unit (BSU). Angles in the polychromator are enlarged for clarity. IF0 is a daylight oppressing filter (see Table 1 for details). IF1 to IF4 are the interference filters, BS is a beam splitter to separate the vibrational Raman lines from the elastic backscattered and rotational Raman signal. In front of the elastic channel a neutral density filter (ND) is mounted. Photomultipliers are marked with PMT.

where $P$ is the laser power, $t$ the integration time, $A$ the telescope area, and $\eta$ the overall detection efficiency.

The statistical error $\Delta T_{\mathrm{Grad}}$ of a temperature gradient measurements is then

$\Delta T_{\mathrm{Grad}}=\frac{\sqrt{2} \Delta T}{\Delta r}$,

with $\Delta r$ being the range interval over which the gradient was calculated.

The two rotational Raman signals can also be used to form a temperature-independent reference signal $P_{\mathrm{RR}}$ for the determination of the particle backscatter coefficient, the particle extinction coefficient, or the water vapor mixing ratio (Behrendt et al., 2002, 2004).

The water vapor mixing ratio (MR) at a distance $r$ is calculated with

$\mathrm{MR}(r)=C \cdot \frac{P_{\mathrm{WV}}(r)}{P_{\mathrm{RR}}(r)} \Gamma(r)$,

where $C$ is a calibration constant, and $P_{\mathrm{WV}}$ and $P_{\mathrm{RR}}$ are the background-corrected signals of the vibrational Raman line of water vapor and the rotational Raman lines of nitrogen and oxygen, respectively (Whiteman et al., 1992; Sherlock et al., 1999). $\Gamma(r)$ is a correction for the different atmospheric extinction $\Gamma$ at the two wavelengths $\lambda_{\mathrm{RR}}$ and $\lambda_{\mathrm{H}_{2} \mathrm{O}}$ :

$\Gamma(r)=\frac{\exp \left[-\int_{r_{0}}^{r} \alpha\left(\lambda_{\mathrm{RR}}, r^{\prime}\right) \mathrm{d} r^{\prime}\right]}{\exp \left[-\int_{r_{0}}^{r} \alpha\left(\lambda_{\mathrm{H}_{2} \mathrm{O}}, r^{\prime}\right) \mathrm{d} r^{\prime}\right]}$.

To determine the calibration constant $C$, a collocated radiosounding can be used. It was found that a correction for the different extinction coefficients of the two wavelengths is negligible for ranges of up to a few kilometers because the difference is less than $0.1 \%$ up to $3 \mathrm{~km}$.

The statistical error of the water vapor measurements can be calculated with Poisson statistics, and one gets

$\Delta \mathrm{MR}=C \frac{P_{\mathrm{WV}}}{P_{\mathrm{RR}}} \sqrt{\frac{P_{\mathrm{WV}}+P_{\mathrm{BWV}}}{P_{\mathrm{WV}}^{2}}+\frac{P_{\mathrm{RR}}+P_{\mathrm{BRR}}}{P_{\mathrm{RR}}^{2}}}$.

While the error analysis based on Poisson statistics determines the so-called shot noise errors, the total statistical error can be estimated with an analysis of the turbulent fluctuations in the atmosphere (Lenschow et al., 2000). For this, data with high temporal resolution are needed in order to resolve the timescale of these fluctuations. The method based on the analysis of the autocovariance function was developed in Senff et al. (1994) and Wulfmeyer (1999a, b) and summarized in Lenschow et al. (2000). Recently, this technique was applied to WV DIAL (e.g., Muppa et al., 2014) and Doppler lidar data (Lenschow et al., 2012), elastic backscatter lidar data (Pal et al., 2010), and water vapor Raman lidar data (Wulfmeyer et al., 2010; Turner et al., 2014a, b). Recently it was applied for the first time to temperature lidar data by using measurements of the UHOH RRL during HOPE (Behrendt et al., 2014). The comparison between the errors derived with Poisson statistics and turbulence analysis confirms that the total statistical error is mainly due to photon shot noise.

\subsection{Current setup}

The rotational Raman lidar of UHOH aims at measurements in the atmospheric boundary layer and lower free troposphere during daytime. A scheme of the setup is shown in Fig. 3. As a laser source, an injection-seeded frequencytripled Nd:YAG laser (Spectra Physics GCR290-50) is used. Only the third harmonic radiation at $354.83 \mathrm{~nm}$ is transmitted into the atmosphere. The human eye is less sensitive to UV wavelengths than to wavelengths in the visible spectrum, and therefore eye safety is achieved at even smaller distances for UV lidars than for lidars using, e.g., the second harmonic radiation of a Nd:YAG laser. In consequence, the first and second harmonics are separated in the transmitter from the third using a Pellin-Broca prism and directed into beam dumps. The separation by a prism is preferable to a beam splitter due 
Table 1. Parameter of interference filters. AOI: angle of incidence; CWL: central wavelength; FHWM: full width at half maximum.

\begin{tabular}{lllllll}
\hline & IF0 & IF1 & IF2a & IF2b & IF3 & IF4 \\
\hline AOI, deg & 0 & 4.8 & 6.0 & 6.0 & $4.8 / 6.2$ & 3.9 \\
CWL, nm & 355 & 354.8 & 354.15 & 354.15 & $353.30 / 353.05$ & 407.7 \\
FWHM & 8.5 & 0.3 & 0.3 & 0.3 & 0.5 & 0.3 \\
Peak transmission & 0.56 & 0.62 & 0.53 & 0.65 & 0.52 & 0.75 \\
Refl. at 354.8 nm & & $<0.1$ & & & & \\
Transm. at 354.8 nm & 0.56 & 0.62 & $<1 \times 10^{-3}$ & $<1 \times 10^{-3}$ & $<1 \times 10^{-6}$ & $<1 \times 10^{-7}$ \\
\hline
\end{tabular}

to the fact that the wavelengths are separated spatially, and definitely no radiation at the other wavelengths remains in the outgoing light. The transmitted power in the UV is around $10 \mathrm{~W}$ at a repetition rate of $50 \mathrm{~Hz}$. The beam is expanded by a factor of 6.5 to prevent damage on the transmitting optics and to achieve eye safety in less than $400 \mathrm{~m}$ distance (taking also hotspots in the beam profile into account). The expanded beam is directed via three mirrors $(10 \mathrm{~cm}$ diameter $)$ onto the first mirror of the beam steering unit. Together with a second mirror, this setup enables us to direct the beam to any azimuth and elevation angle of interest. The whole system is mounted on a mobile platform which can be moved to different measurement sites for field campaigns.

The receiving telescope is of the Ritchey-ChrétienCassegrain type. Its primary mirror has a diameter of $40 \mathrm{~cm}$. To reduce the daylight background, the focused signal passes a pinhole with selectable diameter. The diameter was set to $3 \mathrm{~mm}$ during the HOPE campaign, which results in a full field of view of $0.75 \mathrm{mrad}$. After passing this field stop, the light is parallelized with a lens and then split by a dichroic beam splitter: while light with wavelengths shorter than $375 \mathrm{~nm}$ is transmitted into the main receiver unit, longer wavelengths are reflected. The vibrational-rotational Raman signal of water vapor excited by $354.83 \mathrm{~nm}$ is shifted by wavenumbers around $3657.05 \mathrm{~cm}^{-1}$ (e.g., Avila et al., 2004) from the excitation wavelength and is thus around $407.7 \mathrm{~nm}$ and obtained from the light reflected by the beam splitter. The transmission efficiency of the beam splitter is 0.93 for $355 \mathrm{~nm}$ and 0.02 for $408 \mathrm{~nm}$. Reflectivity at $408 \mathrm{~nm}$ is above 0.95 .

The signal transmitted by the beam splitter passes a daylight-reducing filter IF0 (Eureca, peak transmission of 0.56) and enters the main part of the receiver for the detection of the elastic and rotational Raman signals, which are sequentially mounted (Behrendt and Reichardt, 2000; Behrendt et al., 2002, 2004; Radlach et al., 2008). In front of the first rotational Raman channel, two identical interference filters IF $2 a$ and IF2b are used to achieve sufficient suppression of the elastic signal. In Table 1 all filter parameters are listed. The first filter pair has a transmission of 0.34 for $354.15 \mathrm{~nm}$ and $10^{-6}$ for $354.83 \mathrm{~nm}$. The passbands have a full width at half maximum of $0.3 \mathrm{~nm}$. The filter for extracting the second rotational Raman signal can be toggled between two distinct angles to optimize the performance of temperature measure- ments during conditions of high and low background (see below). For the time being, the change of setting has to be done manually, but the angles are fixed by a pivot tooth. IF3 has a peak transmission of 0.52 and is $0.5 \mathrm{~nm}$ wide. The angles of incidence are $6^{\circ}$ for the interference filters IF $2 a$ and $b$, and 4.8 and $6.2^{\circ}$ for the second interference filter for the highand low-background setting, respectively. The beam divergence in the polychromator is $0.45^{\circ}$ as determined by experimentally validated ray tracing calculations. All narrowband interference filters were manufactured by Materion, Barr Precision Optics \& Thin Film Coating. As photomultiplier for the rotational Raman signals, a Hamamatsu R1924P is used. The elastic channel is equipped with a neutral density filter (transmission of 0.2) to prevent saturation of the photomultiplier (Hamamatsu R7400-U02) in the presence of optically thick clouds in the near range.

In the branch of the water vapor channel, an interference filter (IF4) transmits the desired wavelength range; for details see Table 1. The total suppression has an efficiency better than $10^{-8}$ for $355 \mathrm{~nm}$ and $10^{-6}$ for other wavelengths. The signal is focused on a photomultiplier (Hamamatsu R1924P) for detection.

Presently, two data acquisition systems are used for the four lidar signals. First, there is a transient recorder (LICEL $\mathrm{GmbH}$, Berlin) with three acquisition channels. Each photomultiplier signal is recorded in analog mode with $3.75 \mathrm{~m}$ range resolution and in photon-counting mode with range resolutions of 3.75 and $37.5 \mathrm{~m}$ (see Table 2). The measurement data shown here were all derived with the analog data. In standard operation, backscatter signals of 500 shots are averaged to get a profile with $10 \mathrm{~s}$ integration time. At the beginning of the HOPE campaign, the elastic signal and the two Raman channels were recorded with this system. From early May on, the water vapor detection channel signal was implemented and its signal was recorded with the LICEL data acquisition instead of the elastic signal. The strong elastic signal was then stored with a transient recorder system (Compuscope 14100 card of GaGe Applied Inc.) with resolutions of $3 \mathrm{~m}$ and $1 \mathrm{~s}$, albeit only in analog mode.

The data analysis contains the following steps. First, the photon-counting data are corrected for photomultiplier deadtime effects. A dead time of $4.8 \mathrm{~ns}$ was determined by comparing the analog with the photon-counting signal and used 
Table 2. Signal raw resolution.

\begin{tabular}{llll}
\hline Raw data & Temporal resolution & Spatial resolution & Recording mode \\
\hline Elastic signal & $10 \mathrm{~s}$ & $3.75 \mathrm{~m}$ & Analog + photon-counting \\
& $10 \mathrm{~s}$ & $37.5 \mathrm{~m}$ & Photon-counting \\
Rotational Raman 1 & $1 \mathrm{~s}$ & $3 \mathrm{~m}$ & Analog \\
& $10 \mathrm{~s}$ & $3.75 \mathrm{~m}$ & Analog + photon-counting \\
Rotational Raman 2 & $10 \mathrm{~s}$ & $37.5 \mathrm{~m}$ & Photon-counting \\
& $10 \mathrm{~s}$ & $3.75 \mathrm{~m}$ & Analog + photon-counting \\
Vibrational water vapor & $10 \mathrm{~s}$ & $37.5 \mathrm{~m}$ & Photon-counting \\
\hline
\end{tabular}

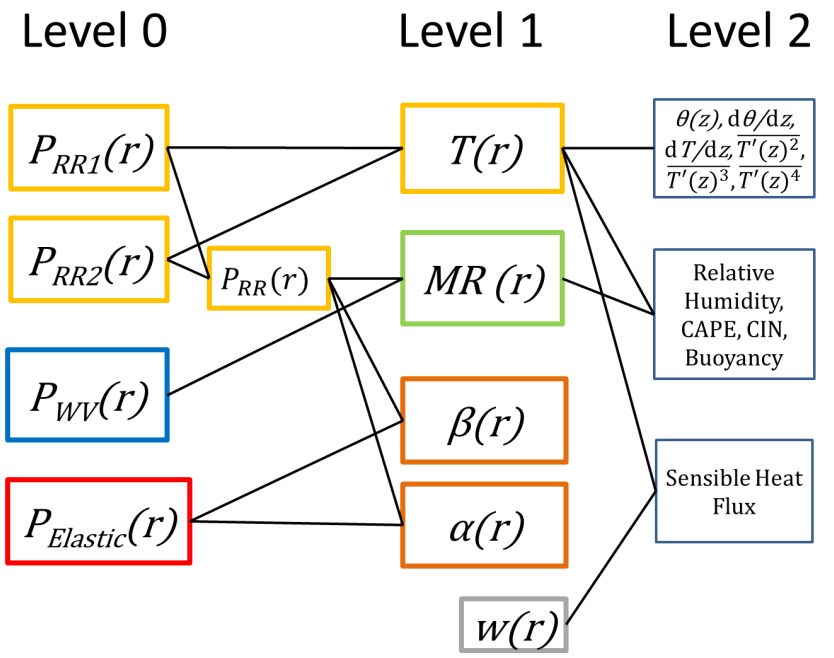

Figure 4. Diagram of the data products. Level 0 data are the background-corrected rotational Raman signals (yellow), the vibrational Raman signal of water vapor (blue), and the elastic backscatter signal (red). A temperature-independent reference signal $P_{\mathrm{RR}}$ is obtained from the temperature-dependent rotational Raman signals. Level 1 data products are temperature $T$, water vapor mixing ratio MR, particle backscatter coefficient $\beta$, and particle extinction coefficient $\alpha$. Higher-level products derived from level 1 data: potential temperature $\theta$, gradient of temperature and potential temperature, higher moments of turbulent temperature fluctuations $T^{\prime}$, relative humidity, buoyancy, CAPE, and CIN. For deriving the sensible heat flux, profiles of the vertical wind $w$, e.g., from a Doppler lidar, are used.

for the correction. It has to be noted that the dead time not only is influenced by the photomultiplier alone but also depends on the data acquisition system. Then, the signals are background-corrected and smoothed in range and time with gliding average lengths that depend on the noise conditions and application. For example, for turbulence analysis (Behrendt et al., 2014) high temporal resolution of $10 \mathrm{~s}$ is needed, while for studies of the temperature gradient a low statistical error is essential. How the statistical error is affected by the averaging can be seen in Eq. (5). Temperature and other data products are then determined with the ana- $\log$ and photon-counting signals separately and merged afterwards if needed. We found that the alternative approach of first merging the analog and photon-counting signals and then deriving the data products in a second step with the merged signals (Newsom et al., 2009) results in unstable temperature calibration functions because the merging procedure produces small erroneous fluctuations which influence the temperature measurements critically. To determine the statistical uncertainties of the data, the analog data are scaled to the photon-counting signals in order to attribute virtual count rates to the analog data (Whiteman et al., 2006). It turned out that this scaling results in accurate shot noise error estimates also for the analog data. In Behrendt et al. (2014) it is shown that the total statistical error depends mainly on the noise error. It is therefore possible to obtain a good error estimation by calculating the shot noise error through Poisson statistics.

From the combination of the two temperature-dependent signals, a temperature-independent molecular reference signal can also be obtained. The weighted sum of the signals with a weighting factor that depends on the system characteristics (Behrendt et al., 2002) can be used as a reference signal for the calculation of the water vapor MR, particle backscatter coefficient $\beta$, and extinction coefficient $\alpha$ (see also Fig. 4); no further vibrational nitrogen Raman signal like that used in other Raman lidar systems is needed. It should also be noted that the statistical uncertainty of the rotational Raman reference signals is lower than the uncertainty of the weaker nitrogen vibrational Raman signal.

The measured temperature profiles can be used to further derive, e.g., profiles of potential temperature $\theta$, temperature gradients, variance, or other higher-order moments of turbulent temperature fluctuations (Behrendt et al., 2014). If profiles of vertical wind $w$ are available with high temporal resolution, e.g., from a Doppler lidar, the sensible heat flux can be calculated. Also other products - like buoyancy (Corsmeier et al., 2011), CAPE (Convective Available Potential Energy), and CIN (Convective Inhibition) (Behrendt et al., 2011) - are possible. 

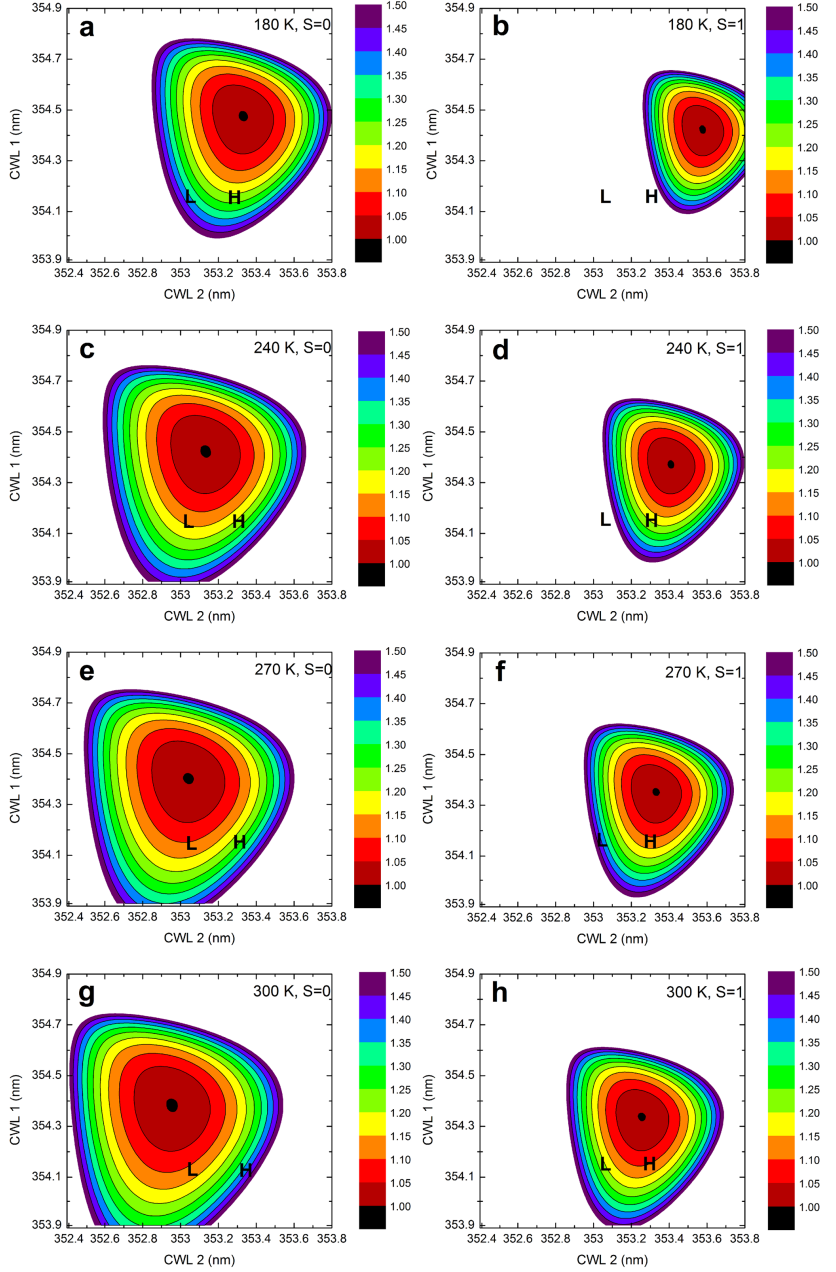

Figure 5. Statistical temperature uncertainty $\Delta T$ for different central wavelengths (CWL) of the RR filters. (a), (c), (e), and (g) are without background $(S=0)$; (b), (d), (f), and (h) are with background $(S=1)$. H denotes the configuration selected for highbackground measurements, L the configuration for low-background measurements. The uncertainty values were normalized to the smallest value of each plot. The laser wavelength is $354.83 \mathrm{~nm}$.

\subsection{Determination of optimum configurations for low and high background}

A switch for the central wavelength of the interference filter of the second rotational Raman channel was introduced during the HOPE campaign. By selecting lines for the second (high $J$ ) rotational Raman backscatter channel with larger spectral distance to the excitation wavelength, one can enhance the temperature sensitivity of the system. But while these lines are more temperature sensitive, they are also weaker in intensity. Consequently, there is a tradeoff between temperature dependence and signal intensity, which results in optimum settings which depend on the signal background relative to the Raman signal intensities (Radlach, 2009). In the following, refined simulation results on this problem of lowest-possible statistical uncertainty of the temperature measurements depending on the background are presented. While the passband of the second rotational Raman channel is changed, the passband of the first rotational Raman channel (low $J$ ) stays constant. The RR1 channel is already so close to the laser wavelength that further change to weaker signals would decrease the blocking of the elastically backscattered light in the signal to critical values.

Refined simulations to what had already been described by Radlach et al. (2008) were performed for the present laser wavelength, with the goal of finding an optimum setting for the central wavelength of the second rotational Raman channel for high and low background. In the following the central wavelength of the first rotational Raman signal detection channel is called CWL1 and the second CWL2. From Eq. (4), the $1 \sigma$ statistical uncertainty of temperature measurements can be calculated for two close temperatures $T_{1}$ and $T_{2}$ with

$$
\Delta T=\frac{\partial T}{\partial Q} \Delta Q \approx \frac{\left(T_{1}-T_{2}\right)}{\left(Q_{1}-Q_{2}\right)} Q \sqrt{\frac{P_{\mathrm{RR} 1}+P_{\mathrm{B} 1}}{P_{\mathrm{RR} 1}^{2}}+\frac{P_{\mathrm{RR} 2}+P_{\mathrm{B} 2}}{P_{\mathrm{RR} 2}^{2}}} .
$$

A simulation of the spectrum at two temperatures $T_{1}$ and $T_{2}$ $5 \mathrm{~K}$ apart combined with the filter transmission curves gives the ratio $Q$ of the two channels. Scaling parameters of the background are the ratio of the background per $0.1 \mathrm{~nm}$ filter bandwidth and the intensity $P_{J}^{\max }$ of the strongest line of the rotational Raman spectrum (Radlach, 2009). This gives as a background

$P_{\mathrm{B}}=S \frac{\Delta \lambda_{\mathrm{FWHM}}}{0.1 \mathrm{~nm}} P_{J}^{\max }$.

For the scaling factor $S$ we chose 1 in the high-background case and 0 in the low-background case. As the intensity of the Raman signal depends on height but the background is constant for all height bins of a profile, the scaling factor $S$ changes for the different heights of a measured profile and, of course, with the solar background and thus latitude, time of the day, and season as well as the laser power and receiver efficiency of the lidar system. During daytime, $S$ will be nearly 0 at low altitudes for a well-designed high-power lidar with high signal to background ratio, but $S$ will increase quickly with altitude as the signal intensity decreases. With optimizations to $S=0$ and $S=1$, one is even prepared for highbackground conditions, e.g., near cumulus clouds at noon. It was found that larger values for $S$ do not change the optimum central wavelengths significantly compared to $S=1$. But as detailed in the following, the differences between $S=0$ and $S=1$ are significant, which is the motivation for the new switch.

In Fig. 5 the results of the simulations are presented for both high and low background for temperature regimes of $180,240,270$, and $300 \mathrm{~K}$. The simulation was performed assuming a beam divergence of $0.45^{\circ}$ on the interference filters in the receiver, which modifies the filter transmission curves accordingly. The beam divergence was chosen in agreement 
Table 3. Relative statistical temperature error for the high- and low-background setting of the center wavelength CWL2 of the interference filter of the second (high $J$ ) rotational Raman channel (H and L, respectively). $S$ is the scaling factor for the background level (see text for details). While $S=0$ stands for no background, $S=1$ characterizes high-background conditions. The resulting relative errors for the selected configurations are bold. With the optimized settings for CWL2 the statistical errors do not exceed $20 \%$ higher values than the absolute optimum for atmospheric temperatures between 240 and $300 \mathrm{~K}$.

\begin{tabular}{l|cccc|cccc}
\hline & \multicolumn{5}{|c|}{$S=0$} & \multicolumn{4}{c}{$S=1$} \\
\hline CWL2 & $180 \mathrm{~K}$ & $240 \mathrm{~K}$ & $270 \mathrm{~K}$ & $300 \mathrm{~K}$ & $180 \mathrm{~K}$ & $240 \mathrm{~K}$ & $270 \mathrm{~K}$ & $300 \mathrm{~K}$ \\
$353.30(\mathrm{H})$ & 1.25 & 1.27 & 1.31 & 1.37 & 1.52 & $\mathbf{1 . 1 7}$ & $\mathbf{1 . 1 3}$ & $\mathbf{1 . 1 4}$ \\
$353.05(\mathrm{~L})$ & 1.36 & $\mathbf{1 . 1 3}$ & $\mathbf{1 . 1 0}$ & $\mathbf{1 . 1 0}$ & 3.46 & 1.70 & 1.39 & 1.21 \\
\hline
\end{tabular}

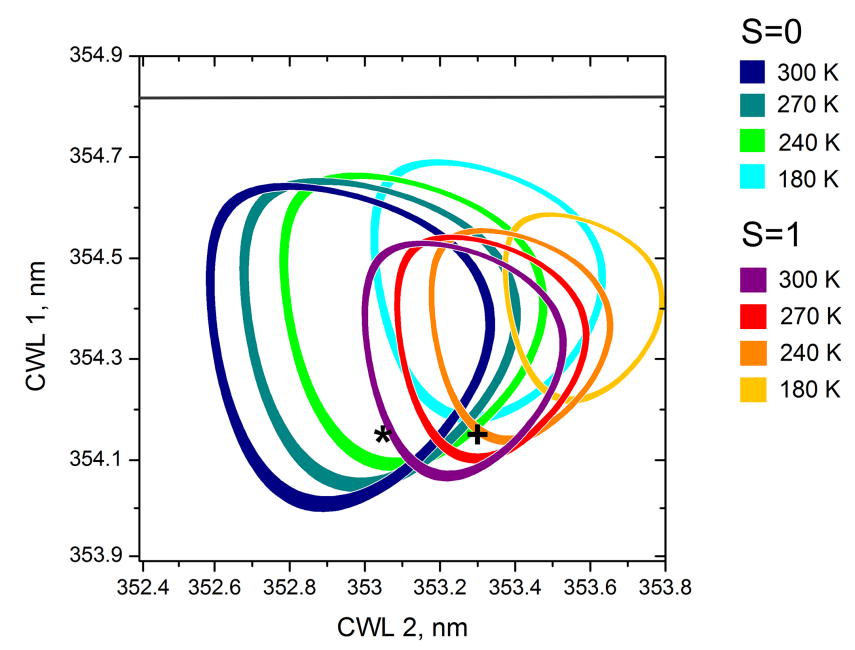

Figure 6. Overview of all cases shown in Fig. 5. The outer and inner borders of the rings mark 1.20 and 1.17 relative uncertainty, respectively. The selected configurations for high- and low-background conditions (marked with + and *, respectively) show lower relative uncertainties than 1.2 for all temperatures between 240 and $300 \mathrm{~K}$ (see also Table 3). The gray line marks the laser wavelength.

with the divergence in the polychromator in the current setup. For divergence values between 0.1 and $1.0^{\circ}$, the optimum wavelengths and iso-lines shift by 0.01 and $0.02 \mathrm{~nm}$, respectively. The relative uncertainty $\Delta T$ is normalized to the smallest value in each case. The values of $\Delta T$ are of course lower during night- than during daytime, but this simulation is made to find an optimum setting within each regime and then compare the optimum settings. The central wavelengths of the first filter are limited to $354.2 \mathrm{~nm}$ and smaller to ensure that the elastic signal is blocked sufficiently for this channel.

The central wavelengths were $354.15 \mathrm{~nm}$ for CWL1 and $353.30 \mathrm{~nm}$ for CWL2 for high-background conditions for the measurements discussed here. With low background at night, this setting is not optimum, and therefore the pair of central wavelengths of 354.15 and $353.05 \mathrm{~nm}$ was used for lowbackground conditions. We use the corresponding angles of incidence mentioned in Table 1. In Fig. 6, an overview of all these temperature regimes is given. One can see that the measurements with our settings are not more than $20 \%$ higher than the minimum uncertainty for all temperatures between 240 and $300 \mathrm{~K}$. But this is only achieved by the two settings for CWL2.

To be able to use the advantages of both wavelengths, it is crucial to be able to toggle between the two settings in a short time period in order to avoid measurement gaps. Furthermore, the setting should be reproducible to avoid changes in calibration or overlap. This is realized by a filter holder which can be fixed by a pivot tooth at two positions. It was built in our workshop and tested on the campaign. Results are shown in Sect. 3.1.

\section{Measurement examples}

\subsection{RR2 switch}

To test the performance of the switch, a $24 \mathrm{~h}$ measurement was made including changes between the $\mathrm{H}$ and $\mathrm{L}$ setting. The switching time coincided with a radiosonde launch during nighttime. In general, "low-background" conditions are defined here as the time where the background is small compared to the rotational Raman signals in the altitude range of interest, i.e., between about half an hour after sunset and half an hour before sunrise. This was the case during the consecutive observation periods with a radiosonde launch at 20:00 UTC and early in the morning. All in all, there were three cases for the evaluation of the performance of the switch.

On average it took about $5 \mathrm{~min}$ to interrupt the data acquisition in a controlled way, change filter position, readjust the stray-light cover, and restart the data acquisition. When changing from high- to low-background setting, the signal intensity in the second Raman channel decreases, which results in a lower ratio $Q$ (Fig. 7). But, as already discussed above, the relative sensitivity to temperature increases. The enhanced sensitivity is seen in Fig. 8, where the ratio between the two channels is normalized to the value at an arbitrary altitude (here the altitude was chosen in which the temperature profile of the radiosonde was $273 \mathrm{~K}$, which was $2.6 \mathrm{~km}$ ). In this visualization the different slope can be seen, which is larger for $\mathrm{L}$ than for $\mathrm{H}$.

Finally, the $Q$ vs. $T$ curves from simulation and experiment (Fig. 9) are compared. For the experimental data, $Q$ 


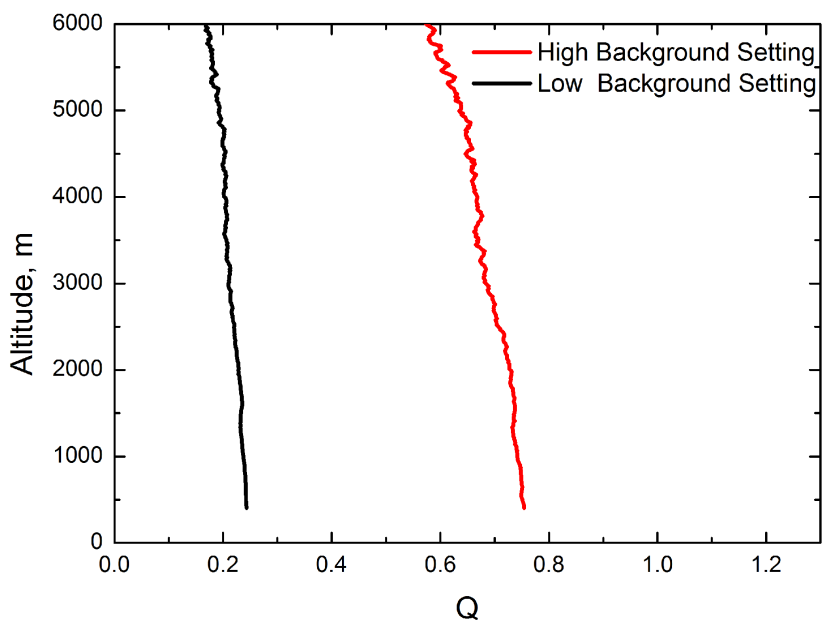

Figure 7. Measured ratio $Q$ of the rotational Raman signals with the high- and low-background setting, $\mathrm{H}$ and $\mathrm{L}$, respectively, at night. The data for the setting $\mathrm{H}$ were collected between 19:38 and 19:58 UTC on 18 May 2013, and data for the setting L just afterwards between 20:05 and 20:25 UTC. The intensity of the RR2 signal decreased by switching to $\mathrm{L}$, hence the smaller ratio $Q$. The rotational signals were smoothed with a gliding average of $105 \mathrm{~m}$ height before the ratio was calculated.

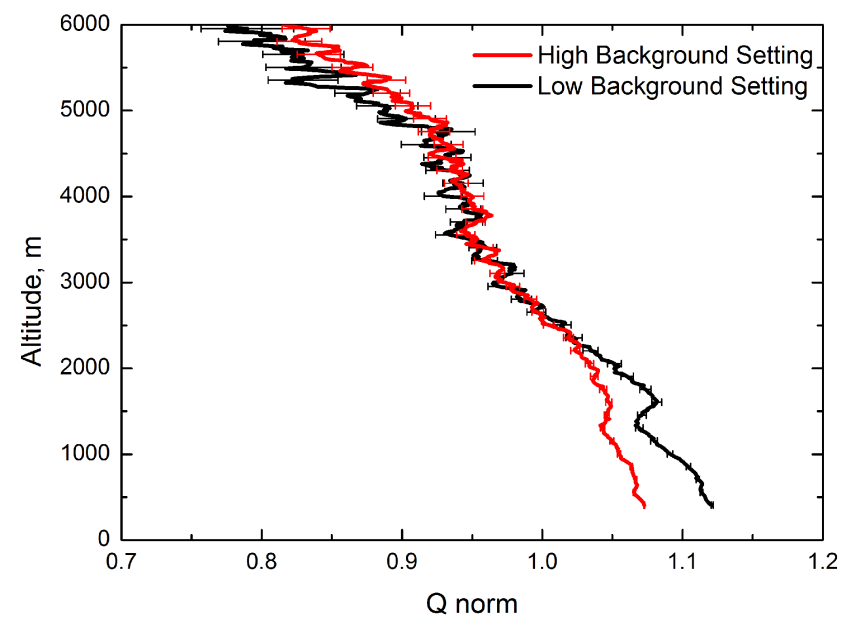

Figure 8. Same as Fig. 7 but normalized to 1 at a height of $2.6 \mathrm{~km}$ to illustrate the higher relative sensitivity of the low-background setting. Error bars show the statistical uncertainties.

values were assigned to $T$ values of the radiosonde at the same height. The simulation calculates the resulting $Q$ for temperatures from 240 to $300 \mathrm{~K}$ in $1 \mathrm{~K}$ steps for the actual filter curves including the central wavelengths. For the low-background setting, simulation and experiment agree very closely within the statistical error bars; for the highbackground, a deviation of $<1.5 \mathrm{~K}$ is found for $Q$ values between 1.0 and 1.05. A comparison with Fig. 8 shows that this is the altitude region where an inversion layer was found. An inversion layer can lead to differences between

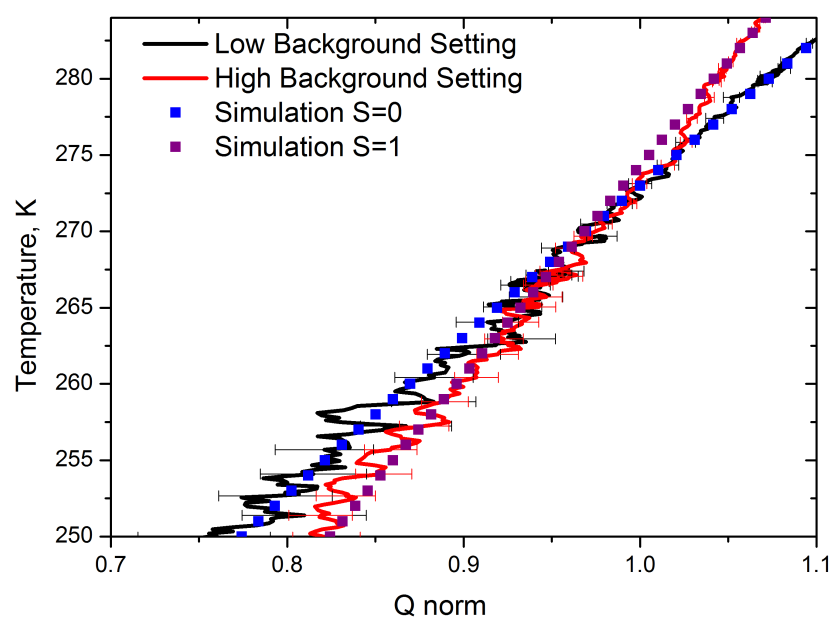

Figure 9. Same as Fig. 8 but against radiosonde temperature at the same height. In addition to the measurements, simulation data for the two settings are shown. In red and black are the measured values for $Q$ with the statistical error, and in blue and violet the corresponding simulation.

radiosonde and lidar measurement due to averaging of the lidar data and sampling of a different air mass. The experimentally determined $Q$ is linked to the temperature values of the radiosounding; a deviation of 1 to $2 \mathrm{~K}$ therefore can be attributed to the inversion. As there are for all other temperatures only deviations within the $1 \sigma$ statistical uncertainties, we conclude that the agreement between experiment and simulation is good.

The statistical errors for different background values with the two settings were calculated. Nighttime measurements were used and, for the high-background case, background added according to a scaling factor of $S=1$ at $1 \mathrm{~km}$. In comparison with actually measured background values at noon with or without cloud coverage, the used background values are higher because the Raman signals of the UHOH RRL are quite strong. Thus, the comparison shows the performance in circumstances which can be considered a worst-case scenario.

Figure 10 shows the statistical errors with low background (measurement from 20:00 UTC, $20 \mathrm{~min}$ average) and both settings. Even during nighttime, there is a background of around 1 photon per bin for the integrated average over 500 laser pulses. Therefore $S$ is not strictly equal to 0 , but, in this case, $S$ was less than 0.1 up to $2.1 \mathrm{~km}$ for the L setting and up to $3.2 \mathrm{~km}$ for the $\mathrm{H}$ setting. $S=1$ was reached at 4.3 and $6.6 \mathrm{~km}$. As expected, the setting L shows smaller errors for low altitudes and is favorable up to $7 \mathrm{~km}$. The simulated error for high background is shown in Fig. 11. The absolute error values are in this case higher than in the case of low background. Below $1 \mathrm{~km}, S$ is less than 1 , which results in a better performance of the low-background setting than the highbackground setting. Above $1 \mathrm{~km}, S$ is larger than 1 and the 


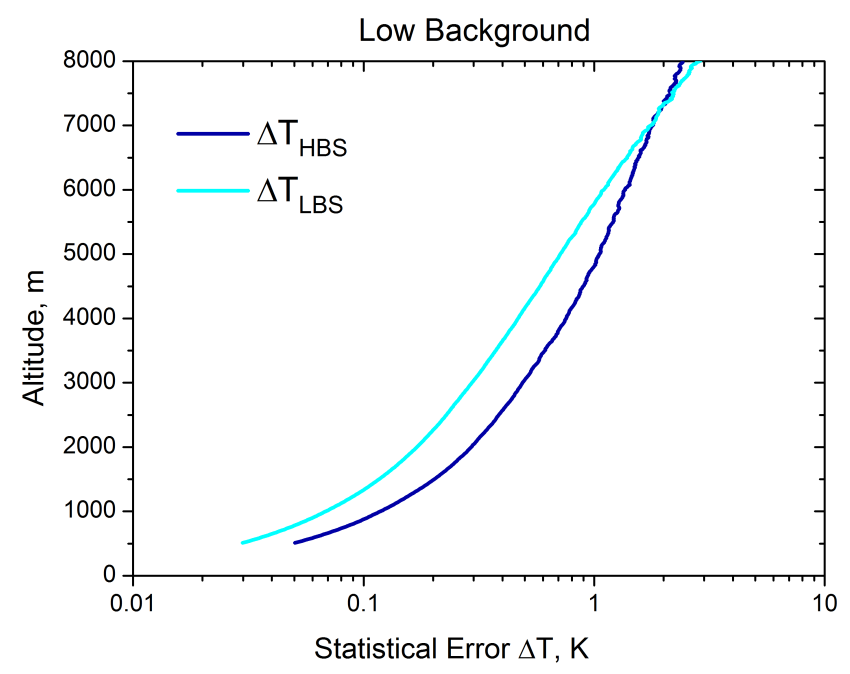

Figure 10. Comparison of the statistical error of the temperature measurements with both settings, $\Delta T_{\mathrm{HBS}}$ and $\Delta T_{\mathrm{LBS}}$, at lowbackground conditions. The profiles were derived from data collected over about $20 \mathrm{~min}$ (55 000 laser shots) and with $105 \mathrm{~m}$ gliding average. Above $7 \mathrm{~km}$ altitude, the high-background configuration shows smaller errors due to the lower atmospheric temperatures at these heights and also the decrease in signal-to-noise ratio.

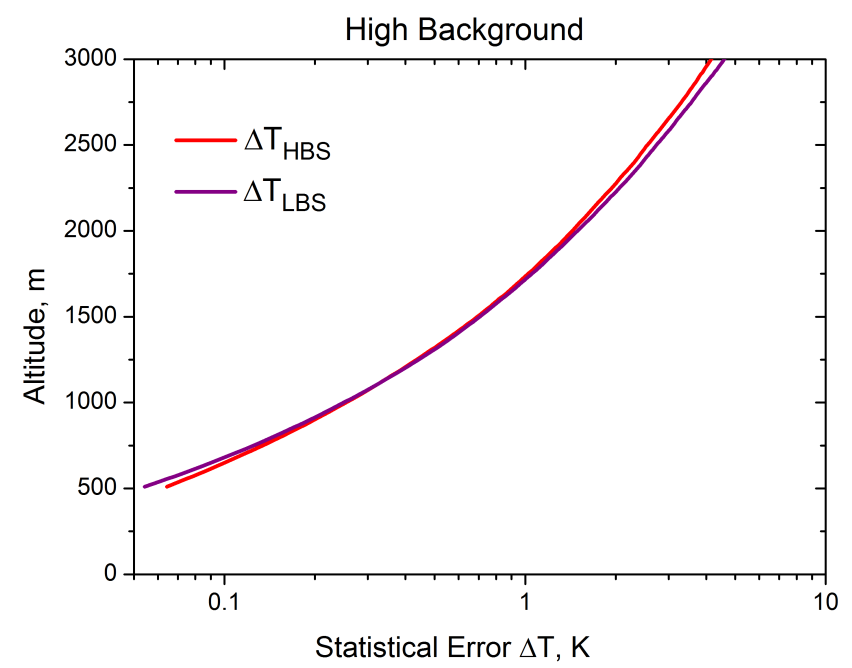

Figure 11. Same as Fig. 10 but for high-background conditions ( $S=1$ in $1 \mathrm{~km}$ altitude). The high-background setting is superior for measurements above $1 \mathrm{~km}$ altitude.

statistical errors are smaller with the high-background configuration.

To show the advantage of the new setting, the ratio between the error with high-background setting $\Delta T_{\mathrm{HBS}}$ and the error with low-background setting $\Delta T_{\text {LBS }}$ was calculated for the different background conditions. The result is shown in Fig. 12. Using setting $L$ is favorable during nighttime up to a height of $7 \mathrm{~km}$, as already seen in Fig. 10. $\Delta T$ is reduced by $70 \%$ for altitudes between 1 and $2 \mathrm{~km}$. Above this altitude

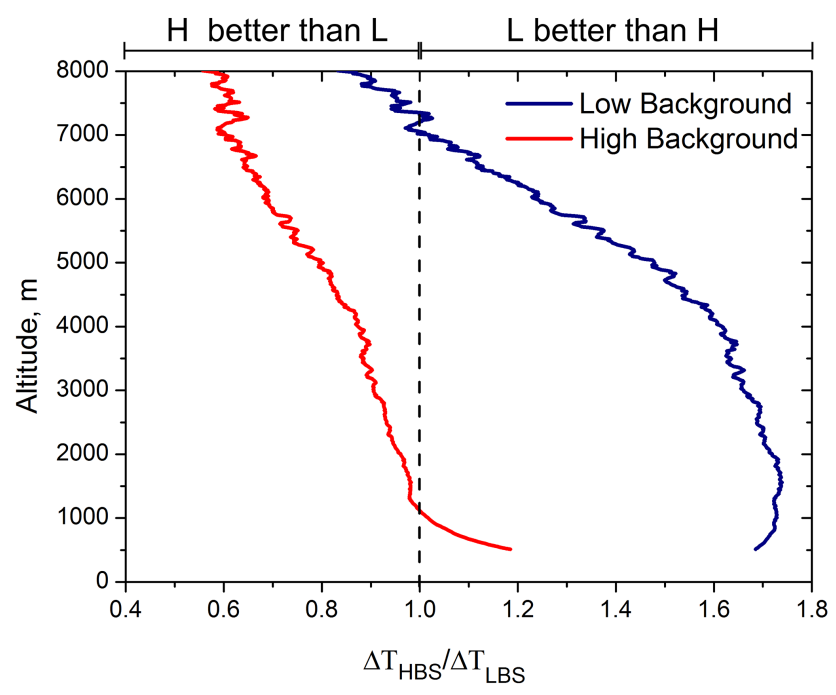

Figure 12. Ratio of high-background-setting uncertainties $\Delta T_{\mathrm{HBS}}$ to low-background-setting uncertainties $\Delta T_{\mathrm{LBS}}$. A ratio above 1 shows better performance for the low-background setting compared to the high-background setting. In cases with no background, this advantage is clearly significant at lower altitudes but decreases with height. On the other hand, the high-background setting is superior already above $1 \mathrm{~km}$ in high-background conditions. But it should be noted that the altitude where the high-background setting becomes preferable depends on the signal-to-background ratio.

the advantage of $\mathrm{L}$ over $\mathrm{H}$ decreases. For high altitudes, $\mathrm{H}$ is still better than L even at night (see Fig. 6 for low temperatures $<240 \mathrm{~K}$ ). This behavior is explained by the fact that the background factor $S$ will be $\geq 1$ at such altitudes. During daytime the signal intensity is high, such that $S<1$ in low altitudes. Here both settings show similar statistical errors with advantages of up to $20 \%$ (at $0.5 \mathrm{~km}$ ) of the low-background configuration. With $S=1$ at $1 \mathrm{~km}$, the setting $\mathrm{H}$ is advantageous above this altitude.

Because the background factor $S$ assumed in the simulations is higher than in reality for the strong signals which are obtained with the UHOH RRL during cloud-free conditions, the altitude where the high-background setting shows an advantage lies above $1 \mathrm{~km}$ unless clouds cause higher background by scattering sunlight. By applying the setting $\mathrm{H}$ during daytime, a good to optimum measurement performance can be guaranteed even under these very high background conditions. It is interesting to note that also smaller laser power would result in higher values of $S$ for all background levels. Thus this optimization approach can be used to adapt the optimum receiver passbands to the system parameters of other lidars.

\subsection{Temperature gradient and humidity}

Figure 13 shows the water vapor MR and the temperature gradient during a $25 \mathrm{~h}$ measurement period between 18 May 2013 at 15:00 UTC and 19 May 2013 at 16:00 UTC. The li- 

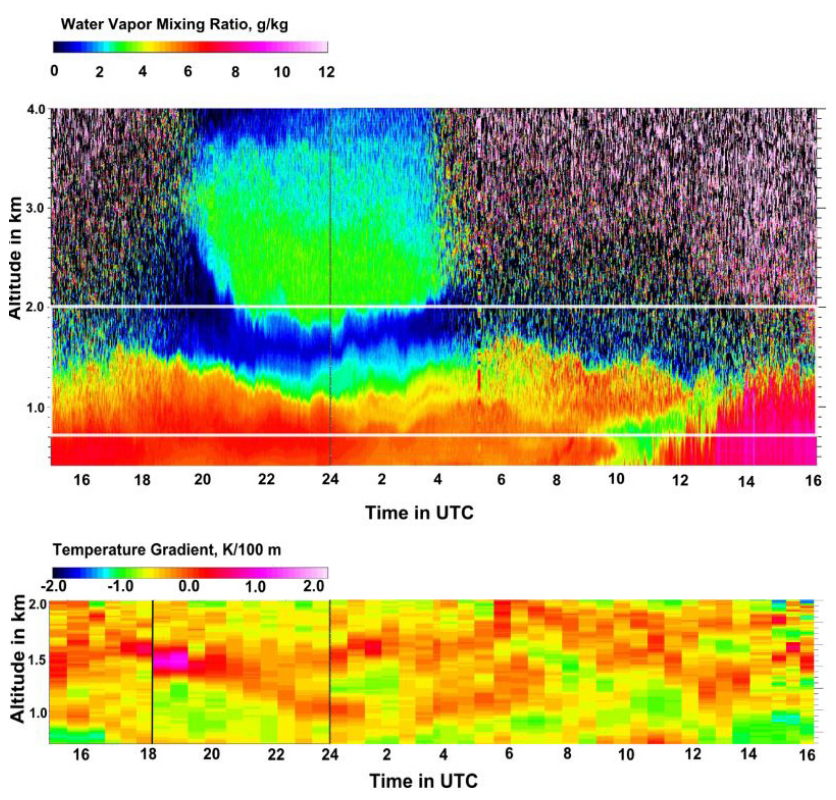

Figure 13. Time series of the water vapor mixing ratio (upper panel) and temperature gradient (lower panel) measured between 15:00 UTC on 18 May 2013 and 16:00 UTC on 19 May 2013. The white lines in the lower panel mark the height range of the data in the upper panel.

dar was pointing vertically during this time period. The setting of IF3 was changed at 20:00 UTC and at 05:00 UTC the next morning. MR data are shown with 1 min averaging. A $78 \mathrm{~m}$ gliding height average was applied to the data. The boundary layer top can be seen due to the gradient between the moist boundary layer and the lower values of MR in the free troposphere. The time series starts at 15:00 UTC, and the boundary layer is still convective at this time. The top of the boundary layer can be found around $1.6 \mathrm{~km}$ at 17:00 UTC. With sunset at 19:22 UTC there is a transition to a stable nocturnal boundary layer. Also a residual layer with a mixing ratio of $3 \mathrm{~g} \mathrm{~kg}^{-1}$ can be observed above the boundary layer with around $6 \mathrm{~g} \mathrm{~kg}^{-1}$ up to $1 \mathrm{~km}$. Due to the lower solar background and the corresponding better measurement range a moist layer between 2 and $3 \mathrm{~km}$ can be observed at night. Sunrise is at 03:39 UTC, which can be seen by the increase of noise around this time. From 10:00 UTC on, the convective boundary layer starts to increase in altitude and shows higher values of mixing ratio (around $8 \mathrm{~g} \mathrm{~kg}^{-1}$ ) than the day before. The height of the boundary layer top does not change significantly from $1.5 \mathrm{~km}$ after 14:00 UTC.

For the altitude region marked with the white box, the temperature gradient is shown in the lower panel. The resolution of temperature gradient data is $30 \mathrm{~min}$ and $105 \mathrm{~m}$. These values have been chosen to monitor the mean boundary layer height continuously. A high positive gradient indicates a temperature inversion. Here one can see a positive gradient at $1.5 \mathrm{~km}$ with a value around $1.2 \mathrm{~K}(100 \mathrm{~m})^{-1}$ be-
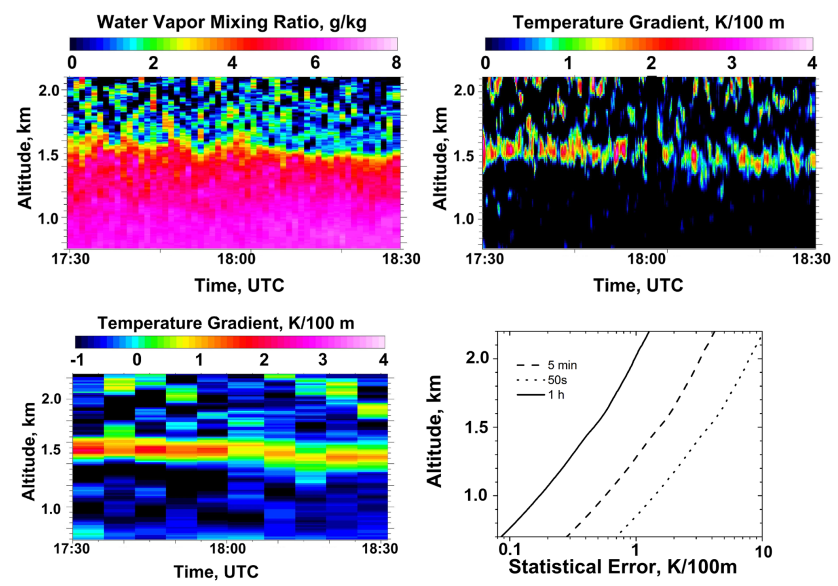

Figure 14. Detail from Fig. 13 of the time period from 17:30 to 18:30 UTC on 18 May. Upper left panel: water vapor mixing ratio with 1 min resolution; lower left panel: temperature gradient with $5 \mathrm{~min}$; and upper left panel: $10 \mathrm{~s}$ profiles and $50 \mathrm{~s}$ gliding time average. Lower right panel: statistical error of temperature gradient measurements.

tween 17:30 and 19:00 UTC, which is remarkable to see in the late afternoon just before sunset. We would have not expected to find such high values in this altitude so late in the day. After sunset the gradient became weaker and split to the top of the nocturnal boundary layer and a residual layer at $1.7 \mathrm{~km}$ which was already observed with the water vapor mixing ratio time series. The residual layer stayed at this altitude during the whole measurement period. From 03:00 till 07:00 UTC another inversion can be seen between 1 and $1.3 \mathrm{~km}$. A strong inversion was present on top of the growing convective boundary layer 10:00 till 15:00 UTC. This demonstrates that with the rotational Raman lidar temperature gradient layers can be identified and observed during longer time periods.

Figure 14 shows the time period from 17:30 to 18:30 UTC in more detail. The water vapor mixing ratio in the upper left panel has the same resolution as in Fig. 13. The temperature gradient is shown with two different temporal resolutions: $50 \mathrm{~s}$ gliding average over $10 \mathrm{~s}$ profiles on the upper right panel, $5 \mathrm{~min}$ on the lower left panel. The statistical uncertainty of the temperature gradient can be seen in the lower right panel. While the statistical error of the $5 \mathrm{~min}$ average is $1.1 \mathrm{~K}(100 \mathrm{~m})^{-1}$ at $1.5 \mathrm{~km}$ altitude, the $50 \mathrm{~s}$ average shows an error of $4 \mathrm{~K}(100 \mathrm{~m})^{-1}$. Therefore it can be used to determine qualitatively the altitude of the highest gradient, but not to identify absolute values. The altitude of the positive gradient and the top of the moist layer agree well for the shown time period even with this high temporal resolution.

The profiles of temperature, potential temperature, temperature gradient, and water vapor mixing ratio and their corresponding statistical uncertainties measured on 19 May 2013 between 13:00 and 13:30 UTC are shown in Fig. 15. This time period near local noon was chosen because the highest 

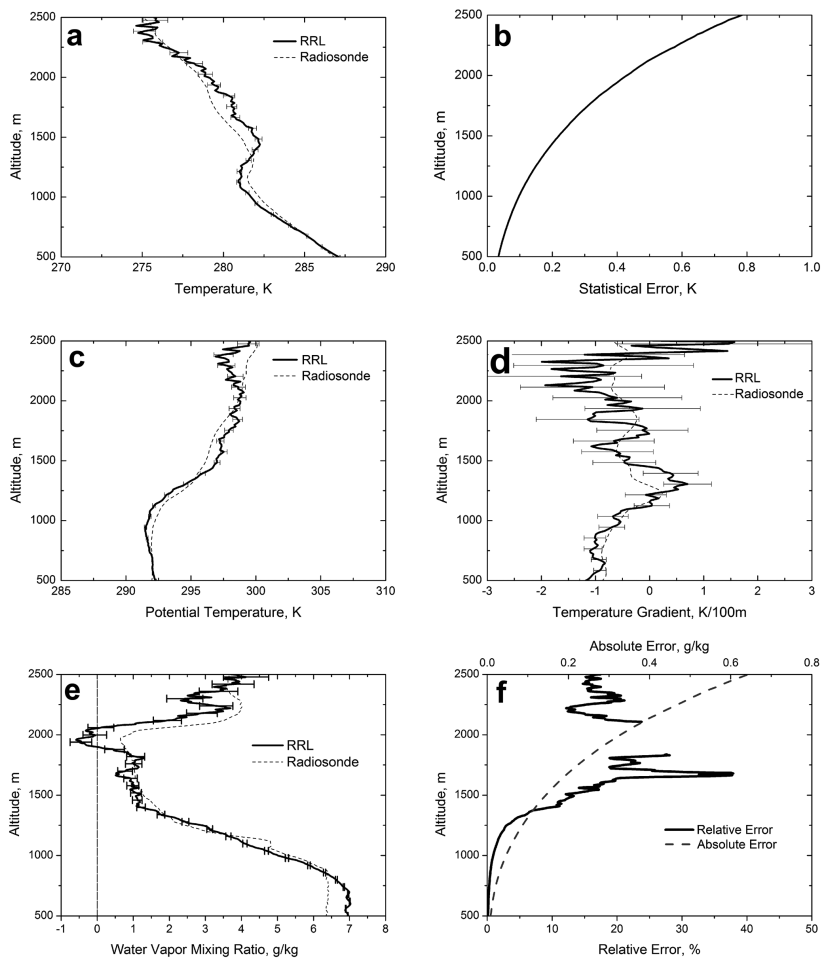

Figure 15. Measurements of the UHOH RRL between 13:00 and 13:30 UTC on 19 May 2013 with data of a local radiosonde launched at 13:00 UTC (dashed) for comparison. (a) Temperature, (b) statistical temperature error, (c) potential temperature (d), temperature gradient (e), water vapor mixing ratio, and (f) absolute and relative error of water vapor mixing ratio. Values of absolute error in the height range where the mixing ratio shows negative values are omitted. Error bars show the statistical errors of the lidar data. Altitudes below $500 \mathrm{~m}$ are affected by non-total overlap and are therefore not shown.

background values during the $25 \mathrm{~h}$ measurement period were found here; these examples thus illustrate the lower limit of the measurement performance, with all other periods having smaller statistical uncertainties. For the temperature profiles an average of 167 raw data profiles was used, and a gliding height average of $105 \mathrm{~m}$ was applied. A pressure profile measured by the radiosonde started at 13:00 UTC was used to calculate potential temperature. In the profiles of temperature, potential temperature, and temperature gradient one can see the characteristics of a well-mixed boundary layer up to about $1100 \mathrm{~m}$. In the interfacial layer above, differences between the measurements of both instruments can be identified. As the lidar measurement is an average over half an hour and the radiosonde profile is just a snapshot, this is reasonable. For the water vapor profile measured with the lidar (Fig. 15e) a $154 \mathrm{~m}$ gliding average was applied. The moist boundary layer, a very dry layer just above, and a second moist layer above $2 \mathrm{~km}$ were found. In the dry layer, the uncertainty of the water vapor Raman lidar measurement gets larger in the absence of moisture due to the small water va-

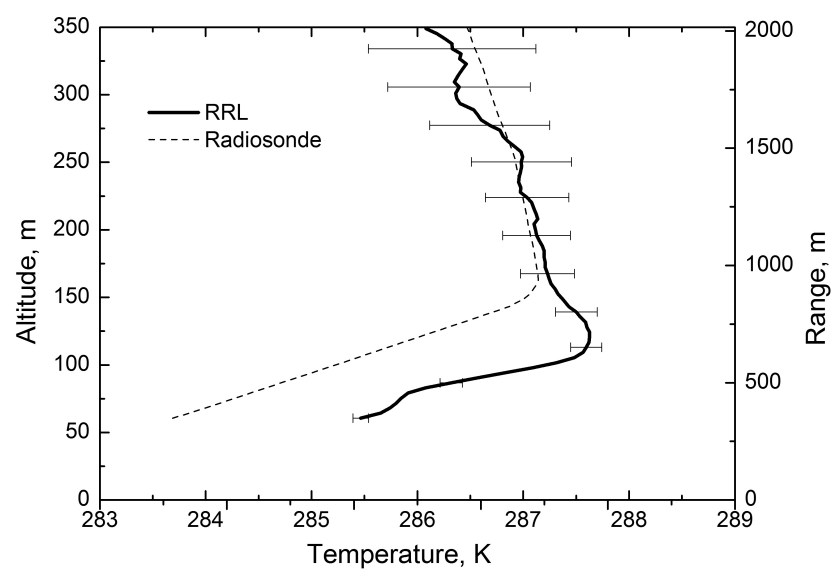

Figure 16. Results of low-elevation measurements: temperature measured with the UHOH RRL and a radiosonde (RS) against height a.g.l. The lidar data were collected from 02:40 to 02:57 UTC on 28 May 2013. The radiosonde measurement was started at 03:00 UTC. The altitude for the lidar profile is calculated from the range and corrected for topography. Lidar data at altitudes below $50 \mathrm{~m}$ are affected by overlap effects.

por Raman backscatter signal. In Fig. 15f the absolute and relative errors of the water vapor mixing ratio are shown. Of course, negative values of the water vapor mixing ratio are physically not possible. But in this case, they appear as measured values as a consequence of the small signal-to-noise ratio due to the small amount of water vapor at this height resulting in a signal which was hardly statistically distinguishable from the daylight background. Note that the $1 \sigma$ statistical range indicates a probability of $68 \%$ that the real value in found within. We do not want to shift these values to 0 because, in doing so, the mean of the data would be biased.

The profiles are shown with noise error bars derived by Eq. (4). A detailed error analysis including errors derived by turbulence analysis is discussed by Behrendt et al. (2014).

\subsection{Low-elevation pointing}

In vertical pointing mode low heights cannot be observed due to overlap effects. These effects can be corrected down to a certain altitude, but a minimum altitude of $300 \mathrm{~m}$ in the case of water vapor mixing ratio or temperature can unfortunately not be overcome with our single-telescope design. One solution for this problem is to perform measurements with small elevation angles. During the measurement shown in Fig. 16, the elevation angle was set to $10^{\circ}$. During HOPE, the measurement site was elevated above its surroundings by 10 to $15 \mathrm{~m}$. This has been taken into account when transferring range to height above ground. The measurement geometry is illustrated in Fig. 17.

In Fig. 16 a comparison between the acquired lidar profile from 02:40 to 02:58 UTC and the radiosonde started at 03:00 UTC is shown. Raw data were treated like vertical ac- 


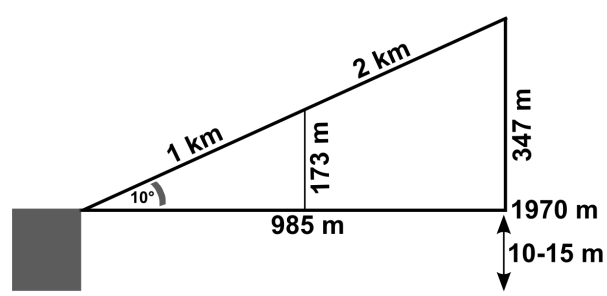

Figure 17. Illustration of the measurement geometry of Fig. 16.

quired profiles and projected to the vertical for the comparison. A positive gradient is present below $100 \mathrm{~m}$ in the lidar profile, whereas in the radiosonde profile it is shifted by $50 \mathrm{~m}$ to higher altitudes. The lidar profile is corrected for the altitude of the surrounding terrain. Whereas the altitudes of the inversion differ, the slope of the temperature profiles is identical. So we conclude that the observations indeed reveal differences of the temperature inversion profile of the nocturnal boundary layer.

\section{Summary and outlook}

In this paper the performance of the rotational Raman lidar of the University of Hohenheim during the HOPE campaign in April to May 2013 is presented.

To optimize the temperature measurements for both low and high background, a switch for the alignment of the interference filter for the second rotational Raman was implemented. It is possible to switch between the configurations in a short time period. The experimental data confirm the optimization simulations. The measurements proved the advantages of the new low-background configuration up to $7 \mathrm{~km}$ during night measurements, especially in altitudes below $4 \mathrm{~km}$. An improvement of the statistical error up to $70 \%$ can be found. Depending on the actual background level present during a measurement, the low-background configuration is also favorable in altitudes below $1 \mathrm{~km}$ during daytime. Due to the high signal intensities of the UHOH RRL, values of $S$ less than 1 can be found in this altitude range. For larger background levels the improvement of the statistical error for using the $\mathrm{H}$ setting is up to $20 \%$. The advantage is not as large when changing from $\mathrm{H}$ to $\mathrm{L}$, but one should keep in mind that a reduction of the statistical uncertainty by $20 \%$ is equivalent to, e.g., an increase in laser power of $44 \%$.

The simulation was performed with the system parameters of the UHOH RRL. Therefore some points have to be taken into account when the results shown here are to be transferred to other systems. To get the exact values for another system, the simulation has to be repeated with the specific system parameters. However, the shifts from the excitation wavelength will be similar for other RRL systems operated in the UV. Additionally, the desired wavelength pairs depend on the temperature range being measured with the highest precision, including the background level in relation to the signal intensity. Bearing all these factors in mind, one can estimate suitable wavelength pairs from Fig. 6.

Furthermore, the UHOH RRL was equipped with an additional channel to detect the vibrational Raman lines of water vapor and now delivers, as a product, the atmospheric water vapor mixing ratio of the atmospheric boundary layer and lower free troposphere during day- and nighttime. As a molecular reference signal, a temperature-independent combination of the two rotational Raman signals is used - not a vibrational Raman signal of nitrogen as commonly used. The statistical error depends on humidity. During daytime the lower $2 \mathrm{~km}$ of the atmosphere can be observed with a time and height averaging of $20 \mathrm{~min}$ and $154 \mathrm{~m}$ gliding average to achieve an absolute noise error less than $0.5 \mathrm{~g} \mathrm{~kg}^{-1}$, which fulfills the requirements for boundary layer studies (Stull, 1988). Time series of water vapor mixing ratio and temperature gradient over a $25 \mathrm{~h}$ period were shown, and the diurnal changes in the boundary layer can be observed. Results from a low level measurement with capture of a strong inversion at $100 \mathrm{~m}$ show the capability to measure in a low-altitude range above ground with the beam steering unit.

Acknowledgements. The HOPE campaign was funded by the German Research Ministry under the project number 01LK1212 A. We thank KIT and the University of Cologne for performing the radiosonde launches.

Edited by: S. Buehler

\section{References}

Achtert, P., Khaplanov, M., Khosrawi, F., and Gumbel, J.: Pure rotational-Raman channels of the Esrange lidar for temperature and particle extinction measurements in the troposphere and lower stratosphere, Atmos. Meas. Tech., 6, 91-98, doi:10.5194/amt-6-91-2013, 2013.

Arshinov, J., Bobrovnikov, S., Serikov, I., Ansmann, A., Wandinger, U., Althausen, D., Mattis, I., and Müller, D.: Daytime operation of a pure rotational Raman lidar by use of a Fabry-Perot interferometer, Appl. Optics, 44, 17, 3593-3603, doi:10.1364/AO.44.003593, 2005.

Avila, G., Fernandez, J. M., Tejeda, G., and Montero, S.: The Raman Spectra and cross-sections of $\mathrm{H}_{2} \mathrm{O}, \mathrm{D}_{2} \mathrm{O}$, and $\mathrm{HDO}$ in the OH/OD-stretching regions, J. Mol. Spectrosc., 228, 38-65, 2004.

Balin, I., Serikov, I., Bobrovnikov, S., Simeonov, V., Calpini, B., Arshinov, Y., and van der Bergh, H.: Simultaneous measurement of atmospheric temperature, humidity, and aerosol extinction and backscatter coefficients by a combined vibrational-purerotational Raman lidar, Appl. Phys. B, 79, 775-782, 2004.

Behrendt, A.: Temperature Measurements with Lidar, Lidar: RangeResolved Optical Remote Sensing of the Atmosphere, Springer, New York, 2005.

Behrendt, A. and Reichardt, J.: Atmospheric temperature profiling in the presence of clouds with a pure rotational Raman lidar by 
use of an interference-filter-based polychromator, Appl. Optics, 39, 1372-1378, 2000.

Behrendt, A., Nakamura, T., Onishi, M., Baumgart, R., and Tsuda, T.: Combined Raman lidar for the measurement of atmospheric temperature, water vapor, particle extinction coefficient, and backscatter coefficient, Appl. Optics, 36, 7657-7666, 2002.

Behrendt, A., Nakamura, T., and Tsuda, T.: Combined temperature lidar for measurements in troposphere, stratosphere and mesosphere, Appl. Optics, 14, 2930-2939, 2004.

Behrendt, A., Wulfmeyer, V., Riede, A., Wagner, G., Pal, S., Bauer, H., Radlach, M., Späth, F.: Three-dimensional observations of atmospheric humidity with a scanning differential absorption lidar, Proc. SPIE, 7475, 74750L, doi:10.1117/12.835143, 2009.

Behrendt, A., Pal, S., Aoshima, F., Bender, M., Blyth, A., Corsmeier, U., Cuesta, J., Dick, G., Dorninger, M., Flamant, C., Di Girolamo, P., Gorgas, T., Huang, Y., Kalthoff, N., Khodayar, S., Mannstein, H., Träumner, K., Wieser, A., and Wulfmeyer, V.: Observation of convection initiation processes with a suite of state-of-the-art research instruments during COPS IOP 8b, Q. J. Roy. Meteor. Soc., 137, 81-100, 2011.

Behrendt, A., Wulfmeyer, V., Hammann, E., Muppa, S. K., and Pal, S.: Profiles of second- to third-order moments of turbulent temperature fluctuations in the convective boundary layer: first measurements with Rotational Raman Lidar, Atmos. Chem. Phys. Discuss., 14, 29019-29055, doi:10.5194/acpd-14-290192014, 2014.

Bhawar, R., Di Girolamo, P., Summa, D., Flamant, C., Althausen, D., Behrendt, A., Kiemle, C., Bosser, P., Cacciani, M., Champollion, C., Di Iorio, T., Engelmann, R., Herold, C., Pal, S., Riede, A., Wirth, M., and Wulfmeyer, V.: The water vapour intercomparison effort in the framework of the convective and orographically-induced precipitation study: airborne-to-groundbased and airborne-to-airborne lidar systems, Q. J. Roy. Meteor. Soc., 137, 325-348, 2011.

Cooney, J.: Measurement of atmospheric temperature profiles by Raman Backscatter, J. Appl. Meteorol., 11, 108-112, 1972.

Corsmeier, U., Kalthoff, N., Barthlott, C., Aoshima, F., Behrendt, A., Di Girolamo, P., Dorninger, M., Handwerker, J., Kottmeier, C., Mahlke, H., Mobbs, S., Norton, E. G., Wickert, J., and Wulfmeyer, V.: Processes driving deep convection over complex terrain: a multi-scale analysis of observations from COPS IOP 9c, Q. J. Roy. Meteor. Soc., 137, 137-155, 2011.

Di Girolamo, P., Marchese, R., Whiteman, D. N., and Demoz, B. B.: Rotational Raman lidar measurements of athmospheric temperature in the UV, Geophys. Res. Lett., 31, L01106, doi:10.1029/2003GL018342, 2004.

Di Girolamo, P., Summa, D., and Ferretti, R.: Multiparameter Raman lidar measurements for the characterization of a dry stratospheric intrusion event, J. Atmos. Ocean. Tech., 26, 1742-1762, 2009.

Immler, F., Engelbart, D., and Schrems, O.: Fluorescence from atmospheric aerosol detected by a lidar indicates biogenic particles in the lowermost stratosphere, Atmos. Chem. Phys., 5, 345-355, doi:10.5194/acp-5-345-2005, 2005.

Kalthoff, N., Adler, B., Wieser, A., Kohler, M., Träumner, K., Handwerker, J., Corsmeier, U., Khodayar, S., Lambert, D., Kopmann, A., Kunka, N., Dick, G., Ramatschi, M., Wickert, J., and Kottmeier, C.: KITcube - a mobile observation platform for con- vection studies deployed during HyMeX, Meteorol. Z., 22, 633647, 2013.

Leblanc, T. and McDermid, I. S.: Accuracy of Raman lidar water vapor calibration and its applicability to longterm measurements, Appl. Optics, 30, 5592-5603, 2008.

Lenschow, D. H., Wulfmeyer, V., and Senff, C.: Measuring secondthough fourth-order moments in noisy data, J. Atmos. Ocean. Tech., 17, 1330-1346, 2000.

Lenschow, D. H., Lothon, M., Mayor, S. D., and Sullivan, P. P.: A comparison of higher-order vertical velocity moments in the convective boundary layer from lidar with in situ measurements and LES, Bound.-Lay. Meteorol., 143, 107-123, 2012.

Mao, J., Hua, D., Wang, Y., Gao, F., and Wang, L.: Accurate temperature profiling of the atmospheric boundary layer using an ultraviolet rotational Raman lidar, Opt. Commun., 282, 3113-3118, 2009.

Melfi, S. H., Lawrence, J. D., McCormick, M. P.: Observation of Raman scattering by water vapor in the atmosphere, Appl. Phys. Lett., 15, 295-297, 1969.

Muppa, S. K., Behrendt, A., Späth, F., Wulfmeyer, V., Metzendorf, S., and Riede, A.: Turbulent humidity fluctuations in the convective boundary layer: case studies using DIAL measurements, Bound. Lay. Meteorol., submitted, 2014.

Newsom, R. K., Turner, D. D., Mielke, B., Clayton, M., Ferrare, R., and Sivaraman, C.: Simultaneous analog and photon counting detection for Raman lidar, Appl. Optics, 20, 3903-3914, 2009.

Pal, S., Behrendt, A., and Wulfmeyer, V.: Elastic-backscatter-lidarbased characterization of the convective boundary layer and investigation of related statistics, Ann. Geophys., 28, 825-847, doi:10.5194/angeo-28-825-2010, 2010.

Radlach, M.: A scanning eye-safe rotational Raman lidar in the ultraviolet for measurements of tropospheric temperature fields, doctoral thesis, Stuttgart, 2009.

Radlach, M., Behrendt, A., and Wulfmeyer, V.: Scanning rotational Raman lidar at $355 \mathrm{~nm}$ for the measurement of tropospheric temperature fields, Atmos. Chem. Phys., 8, 159-169, doi:10.5194/acp-8-159-2008, 2008.

Schotland, R. M.: Errors in the lidar measurement of atmospheric gases by differential absorption, J. Appl. Meteorol., 13, 71-77, 1974.

Schwitalla, T. and Wulfmeyer, V.: Radar data assimilation experiments using the IPM WRF Rapid Update Cycle, Meteorol. Z. 1, 79-102, 2014.

Senff, C., Bösenberg, J., and Peters, G.: Measurements of water vapor flux profiles in the convective boundary layer with lidar and radar-RASS, J. Atmos. Ocean. Tech., 11, 85-93, 1994.

Sherlock, V., Garnier, A., Hauchecorne, A., and Keckhut, P.: Implementation and validation of a Raman lidar measurement of middle and upper tropospheric water vapor, Appl. Optics, 27, 58385850, 1999.

Stevens, B. and Bony, S.: What are climate models missing?, Science, 340, 1053-1054, 2013.

Stull, R. B.: An Introduction to Boundary Layer Meteorology, Springer, Heidelberg, New York, 1988.

Su, J., McCormick, M. P., Wu, Y., Lee III, R. B., Lei, L., Liu, Z., and Leavor, K. R.: Cloud temperature measurement using rotational Raman lidar, J. Quant. Spectrosc. Ra., 125, 45-50, 2013.

Turner, D. D. and Goldsmith, J. E. M.: Twenty-four-hour Raman lidar water vapor measurements during the atmospheric radiation 
measurement program's 1996 and 1997 water vapor intensive observation periods, J. Atmos. Ocean. Tech., 16, 1062-1076, 1999.

Turner, D. D., Ferrare, R. A., Wulfmeyer, V., and Scarino, A. J.: Aircraft evaluation of ground-based Raman lidar water vapor turbulence profiles in convective mixed layers, J. Atmos. Ocean. Tech., 31, 1078-1088, 2014a.

Turner, D. D., Wulfmeyer, V., Berg, L. K., and Schween, J. H.: Water vapor turbulence profiles in stationary continental convective mixed layers, J. Geophys. Res., 119, 11 pp., doi:10.1002/2014JD022202, 2014b.

Wagner, G., Behrendt, A., Wulfmeyer, V., Späth, F., and Schiller, M.: High-power Ti:sapphire laser at $820 \mathrm{~nm}$ for scanning ground-based water-vapor differential absorption lidar, Appl. Optics, 52, 11, 2454-2469, 2013.

Whiteman, D. N., Melfi, S. H., and Ferrare, R. A.: Raman lidar system for the measurement of water vapor and aersosols in the Earth's atmosphere, Appl. Optics, 31, 16, 3068-3082, 1992.

Whiteman, D. N., Demoz, B., di Girolamo, P., Comer, J., Veselovskii, I., Evans, K., Wang, Z., Sabatino, D., Schwemmer, G., Gentry, B., Lin, R-F., Behrendt, A., Wulfmeyer, V., Browell, E., Ferrare, R., Ismail, S. and Wang, J.:Raman Lidar Measurements during the International H2O Project. Part II: Case Studies, J. Atmos. Oceanic Technol., 23, 170-183, 2006.
Wulfmeyer, V.: Investigation of turbulent processes in the lower troposphere with water-vapor DIAL and Radar-RASS, J. Atmos. Sci., 56, 1055-1076, 1999a.

Wulfmeyer, V.: Investigations of humidity skewness and variance profiles in the convective boundary layer and comparison of the latter with large eddy simulation results, J. Atmos. Sci., 56, 1077-1087, 1999b.

Wulfmeyer, V. and Bösenberg, J.: Ground-based differential absorption lidar for water-vapor profiling: assessment of accuracy, resolution, and meteorological applications, Appl. Optics, 37, 38253844, 1998.

Wulfmeyer, V. and Feingold, G.: On the relationship between relative humidity and particle backscattering coefficient in the marine boundary layer determined with differential absorption lidar, J. Geophys. Res., 105, 4729-4741, 2000.

Wulfmeyer, V., Pal, S., Turner, D. D., and Wagner, E.: Can water vapour Raman lidar resolve profiles of turbulent variables in the convective boundary layer?, Bound.-Lay. Meteorol., 136, 253284, 2010.

Zeyn, J., Lahmann, W., and Weitkamp, C.: Remote daytime measurements of tropospheric temperature profiles with a rotational Raman lidar, Opt. Lett., 21, 16, 1301-1303, 1996. 